This item was submitted to Loughborough's Research Repository by the author.

Items in Figshare are protected by copyright, with all rights reserved, unless otherwise indicated.

\title{
A polymer electrolyte membrane fuel cell model with multi-species input
}

PLEASE CITE THE PUBLISHED VERSION

PUBLISHER

(C) IMechE / Professional Engineering Publishing

VERSION

VoR (Version of Record)

LICENCE

CC BY-NC-ND 4.0

REPOSITORY RECORD

Rama, Pratap, Rui Chen, and R.H. Thring. 2009. "A Polymer Electrolyte Membrane Fuel Cell Model with Multispecies Input”. figshare. https://hdl.handle.net/2134/4499. 
This item was submitted to Loughborough's Institutional Repository (https://dspace.lboro.ac.uk/) by the author and is made available under the following Creative Commons Licence conditions.

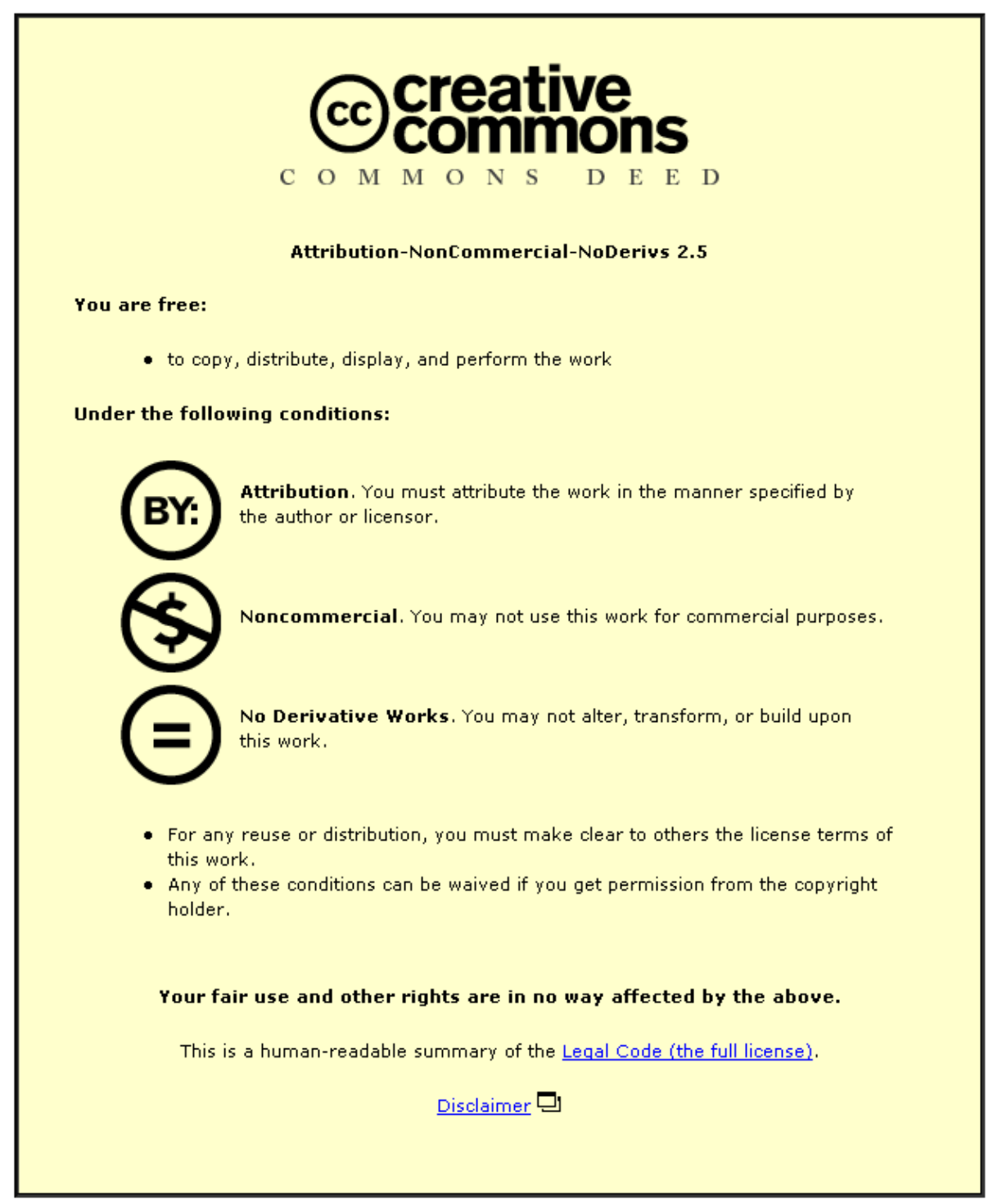

For the full text of this licence, please go to: http://creativecommons.org/licenses/by-nc-nd/2.5/ 


\title{
A polymer electrolyte membrane fuel cell model with multi-species input
}

\author{
P Rama, R Chen*, and R Thring \\ Department of Aeronautical and Automotive Engineering, Loughborough University, Loughborough, UK
}

The manuscript was received on 30 April 2004 and was accepted after revision for publication on 13 January 2005.

DOI: $10.1243 / 095765005 X 7600$

\begin{abstract}
With the emerging realization that low temperature, low pressure polymer electrolyte membrane fuel cell (PEMFC) technologies can realistically serve for power-generation of any scale, the value of comprehensive simulation models becomes equally evident. Many models have been successfully developed over the last two decades. One of the fundamental limitations among these models is that up to only three constituent species have been considered in the dry pre-humidified anode and cathode inlet gases, namely oxygen and nitrogen for the cathode and hydrogen, carbon dioxide, and carbon monoxide for the anode. In order to extend the potential of theoretical study and to bring the simulation closer towards reality, in this research, a 1D steady-state, low temperature, isothermal, isobaric PEMFC model has been developed. The model accommodates multi-component diffusion in the porous electrodes and therefore offers the potential to further investigate the effects of contaminants such as carbon monoxide on cell performance. The simulated model polarizations agree well with published experimental data. It opens a wider scope to address the remaining limitations in the future with further developments.
\end{abstract}

Keywords: multi-component diffusion, water-gas shift reaction, CO crossover, simulation

\section{INTRODUCTION}

The critical element of a model is the founding theory, and for a polymer electrolyte membrane fuel cell (PEMFC) this encompasses electrochemistry, thermodynamics, and fluid mechanics. Although the founding theory for different models may be common, the manipulation of the theory can lead to different systems of equations and different assumptions. More specifically, models based largely on theory may comprehensively consider all of the phenomenological processes, but would be difficult to solve with an abundance of parametric constants that are not necessarily easy to define. Alternatively, empirical models based upon experimental data could provide more accurate results within a certain operating range for specific cell designs, but would not necessarily be universal in applicability, and possibly would not reflect a full

${ }^{*}$ Corresponding author: Department of Aeronautical and Automotive Engineering, Loughborough University, Loughborough LE11 3TU, UK. understanding of the processes involved. The intermediate solution would therefore lie in a semiempirical model that identifies the key processes, but uses experimental results to assist in solving the key equations without over-computation. There are a number of key historical models that have been developed.

Fuller and Newman [1] introduced concentrated solution theory to describe species flux in the membrane. Three species were considered in the model: polymer with acid groups, hydrogen ions, and water. Mass transportation was considered in 1D across the cell, while thermal management was introduced in the transverse along-the-gas-channel direction via energy balance. Each channel gas was treated as a heat removal medium and the effects of different thermal conductivities of these gases were analysed with respect to cell performance. It was found that the hydration of the membrane was sensitive to the rate of heat removal such that low rates of heat removal, i.e. low channel gas thermal conductivities, would result in poor cell performance. 
Bernardi and Verbrugge $[\mathbf{2}, \mathbf{3}]$ developed a mathematical model which divided the cell into seven regions: gas flow channels, gas diffusers and catalyst layers for cathode and anode, and a membrane region in between. Species flux within these regions was described using dilute solution theory, where the Nernst-Planck-Einstein equation was used to describe the flux due to migration, diffusion, and convection. Cell operation was assumed to be isothermal, and gas-phase pressures were assumed to be constant owing to the low gas-phase viscosity. Correspondingly, the liquid-phase pressures were assumed to be variable and pressure gradients were introduced to the model via Schlogl's velocity equation. The model assumed that the membrane was fully hydrated.

Springer et al. [4] developed a semi-empirical model. Dilute solution theory was used solely to describe water flux in the membrane. The form of the flux equation employed, however, coupled the flux due to migration and diffusion as a function of the chemical potential of water. The cell was assumed to be isobaric; therefore pressure-driven convective fluxes were not considered. In a PEMFC, a counter-flux of water from cathode to anode exists. It is caused by the flux of protons from the anode to the cathode, which drags water molecules back to the cathode end of the membrane. This phenomenon was mathematically simulated in the model, in part, using experimental data. The fundamental argument presented by the model was that the counter-acting water fluxes caused a gradient in water content to build up across the membrane, such that the membrane was not always uniformly hydrated. This gradient from anode to cathode increased with respect to operating current density causing the membrane to loose its proton-conductivity, which increased the overall cell resistance and reduced the output cell voltage.

Amphlett et al. [5] developed a different semi-empirical model using experimental performance data from the Ballard Mark IV fuel cell. The model assumed isobaric and isothermal operation. Electrode transport was described using the Stefan-Maxwell equation, and the activation and the ohmic overvotlages were defined by applying linear regression to experimental data. Membrane transport was not mathematically modelled. The calculated cell performance curves correlated well with experimental results.

One of the fundamental limitations among these models is that only up to two constituent species were considered in the dry pre-humidified anode and cathode inlet gases. This limitation extends to other 2D computational models where multi-component transport is included but restricted to the inclusion of oxygen, nitrogen, and water in the inlet cathode feed after humidification $[\mathbf{6}, \mathbf{7}]$. This reflects only the ideal case. Tropospheric air would have at least 10 constituents whereas reformed fuel supplies would typically contain carbon dioxide $\left(\mathrm{CO}_{2}\right)$ and carbon monoxide $(\mathrm{CO})$.

CO molecules, for example, adsorb more readily than hydrogen onto platinum-based catalyst sites. With its presence, the surface fraction available for hydrogen chemisorption is compromised [8-12]. Correspondingly, the activation energy increases for the hydrogen oxidation process, which increases the anodic activation overpotential. Although it has received little attention, carbon monoxide is known to permeate the membrane and consequently degrade the performance of the cathode catalyst [13]. It follows that a mass transport of carbon monoxide over the membrane exist. It is also acknowledged that Nafion membranes are susceptible to a loss mechanism attributed to the crossover of $\mathrm{H}_{2}$ in the membrane from the anode side to the cathode side [14]. In the cathode catalyst layer, trace amounts of diffused $\mathrm{H}_{2}$ would react chemically with $\mathrm{O}_{2}$ from the cathodic oxidant supply, to form water. This has the effect of reducing fuel efficiency. At the same time, excessive crossover of $\mathrm{H}_{2}$ to the cathode side is said to cause 'hot-spots' that could destroy the membrane electrode assembly (MEA) and compromise the safety of the cell.

In this research, a 1D isothermal, steady-state PEMFC model has been developed based on a number of key publications in the area. In the model, the fuel cell consists of five regions, as illustrated in Fig. 1. Gas chambers for anode and cathode transport humidified fuel and air, respectively, and also remove unused gases and water. In reality, electrodes are bonded to the membrane by a carbon gas-diffuser/catalyst layer/membrane matrix. In the model, this has been assumed to be an infinitely thin interfacial layer. The hydrogen-ion conducting membrane lies between the anode and cathode ends. The model introduced a multi-component diffusion mechanism to electrode gas transportation. The mass transport model of the cell was completed by considering water transport in the membrane region. The transport processes in the two electrodes and the membranes were assumed to be simultaneous and inter-dependent. The transport of $\mathrm{CO}$ across the cell from the anode inlet has been studied due to its impact on cell performance. The simulated polarizations by the model agreed well with experimental data obtained from the Ballard Mark IV fuel cell tested and published by Amphlett et al. [5] .

\section{BASIC PEMFC MODEL}

The newly developed multi-species PEMFC model can generally be divided into two parts: the basic model and the multi-species mass transportation 


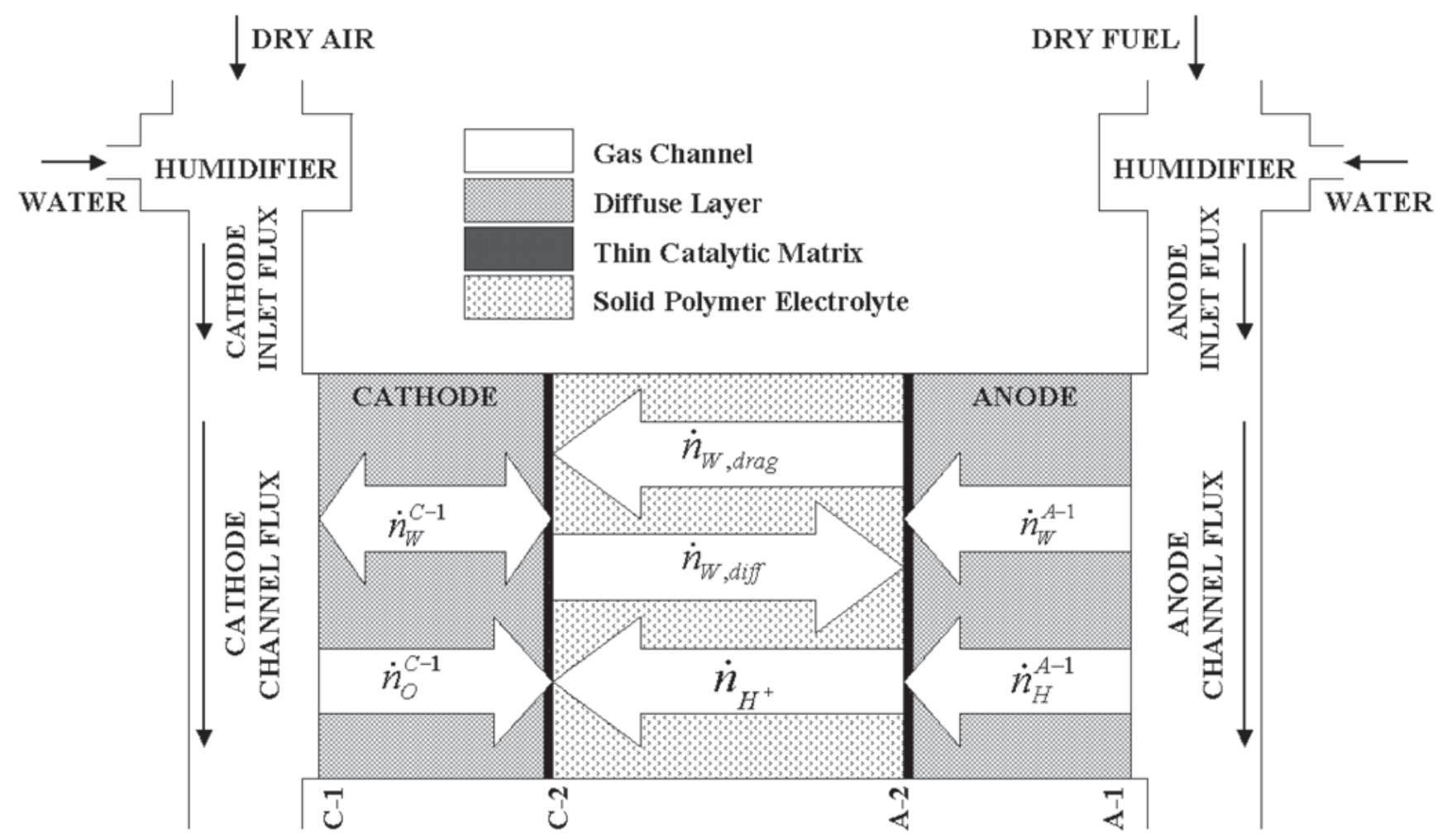

Fig. 1 Five regions of the polymer electrolyte fuel cell

in the diffusion portion of the anode and the cathode electrodes. The assumptions used in the model are:

- the total pressures in the channels are constant and equal;

- both anode and cathode streams are humidified to saturation to their respective saturation temperatures;

- the fuel cell operates under isothermal steadystate conditions;

- the heat conduction by channel flows is negligible;

- the gas mixtures behave as ideal gases;

- the water exists in vapour form [4];

- when the local water activity exceeds unity, the excess liquid water exists as small droplets of negligible volume;

- the diffusion coefficient of water in the membrane is a function of the water content;

- the water drag is a function of the local water content;

- there is zero crossover of $\mathrm{H}_{2}$ and $\mathrm{O}_{2}$ in the membrane region;

- the only fluxing species are the hydrogen ions by electric field, the diffusion and dragging of water vapour, and diffusion of CO through the hydrated membrane region;

- the concentration of water in the membrane is much less than the electrolyte concentration.

\subsection{Thermodynamic equilibrium potential}

The thermodynamic equilibrium potential is obtained using the relevant form of the Nernst equation [5].

$$
E=E^{\circ}+4.3085 \times 10^{-5} T\left[p_{\mathrm{H}_{2}} p_{\mathrm{O}_{2}}^{1 / 2}\right]
$$

where

$$
E^{\circ}=1.229-0.85 \times 10^{-3}(T-298.15)
$$

The useful amount of work, the electric energy, is obtained from a fuel cell only when a reasonably large current is drawn. Under such conditions, the cell potential decreases from its equilibrium potential because of irreversible losses. There are generally two transport-dependant sources that contribute to these irreversible losses; the ohmic polarization $\left(\eta_{\text {ohm }}\right)$ and the activation polarization $\left(\eta_{\text {act }}\right)$.

\subsection{Activation polarization}

The activation polarization is described using electrode kinetics, which is defined by the Butler-Volmer equation

$$
J=j_{0}\left[\exp \left(-\frac{\alpha n F \eta}{R T}\right)-\exp \left(-\frac{(1-\alpha) n F \eta}{R T}\right)\right]
$$


The exchange current density, $j_{0}$, depends upon the rate-controlling process. For the cathode, this is the reduction of oxygen [15]

$$
j_{0}=n F K\left(c_{\mathrm{H}^{+}}\right)^{1-\alpha_{\mathrm{C}}}\left(c_{\mathrm{O}_{2}}\right)^{1-\alpha_{\mathrm{C}}}\left(c_{\mathrm{H}_{2} \mathrm{O}}\right)^{\alpha_{\mathrm{C}}}
$$

whereas for the anode, it is the chemisorption of hydrogen

$$
j_{0}=2 k^{\prime} \exp \left(\frac{(1-\gamma) \Delta G_{\mathrm{c}}}{R T}\right)
$$

where $\gamma$ can be given as $1-\alpha_{\mathrm{A}}[\mathbf{1 5}]$.

Rearranging the Butler-Volmer equation and superimposing losses for both electrodes yields an equation that contains parametric coefficients. These can be grouped together to yield a total activation polarization equation of the form [5]

$$
\eta_{\text {act }}=\xi_{1}+\xi_{2} T+\xi_{3} T \ln \left(c_{\mathrm{O}_{2}}\right)+\xi_{4} \ln (i)
$$

It has been suggested that these parametric coefficients are in fact constants [5]. Amphlett et al. [5] applied a linear regression technique to experimental data from the Ballard Mark IV fuel cell to determine these constants. The following resulting equation gives the total activation polarization and has been applied to the current model

$$
\begin{aligned}
\eta_{\text {act }}= & -0.9514+0.00312 T-0.000187 T[\ln (i)] \\
& +7.4 \times 10^{-5} T\left[\ln \left(c_{\mathrm{O}_{2}}^{\mathrm{C}-2}\right)\right]
\end{aligned}
$$

The concentration of oxygen is defined by Henry's Law [5]

$$
c_{\mathrm{O}_{2}}^{\mathrm{C}-2}=\frac{p_{\mathrm{O}_{2}}^{\mathrm{C}-2}}{5.08 \times 10^{6} \exp (-498 / T)}
$$

The motivation behind the use of equation (7) is that it is, as intended, simple to use and its results agreed well with certain experimental results [4]. Also, equations (4) and (5) have addressed the key phenomenological processes occurring at electrodes, and considered the activation energy required at the anode, although its contribution to activation losses is small when compared with the cathodic activation losses.

\subsection{Ohmic polarization}

The total drop in the cell potential due to ohmic resistance consists of the combined resistance to electron and the proton transport, and has been defined by Ohm's law in the model [5]

$$
\eta_{\mathrm{ohmic}}^{\text {total }}=\eta_{\mathrm{ohmic}}^{\text {eletronic }}+\eta_{\mathrm{ohmic}}^{\text {protons }}=-i R^{\text {internal }}
$$

where $R^{\text {internal }}$ is the total internal resistance of the fuel cell.
The internal resistance can be derived from Nernst-Planck-Einstein equation when applied to hydrogen ion flux in the membrane [5]

$$
\begin{aligned}
R^{\text {internal }}= & R^{\text {electronic }}+\frac{R T}{F^{2} A} \int_{0}^{l_{\mathrm{m}}} \frac{1}{D_{\mathrm{H}^{+}} c_{\mathrm{H}^{+}}} \mathrm{d} z \\
& +\frac{R T}{F i} \int_{0}^{l_{\mathrm{m}}} \frac{1}{c_{\mathrm{H}^{+}}} \cdot \frac{\mathrm{d} c_{\mathrm{H}^{+}}}{\mathrm{d} z} \mathrm{~d} z-\frac{R T}{F i} \int_{0}^{l_{\mathrm{m}}} \frac{v}{D_{\mathrm{H}^{+}}} \mathrm{d} z
\end{aligned}
$$

However, in the membrane, the water flux and the hydrogen ion flux occur simultaneously. The interaction between the two influences the transportation mechanisms of each flux. The Nernst-PlanckEinstein equation can also be applied to water flux. In such a case, although comprehensive, it would not be experimentally viable to define all characteristic variables and would be difficult to simulate theoretically.

An alternative solution is to select the key variables that characterize the internal resistance and experimentally determine the remaining coefficients using the same approach as that taken in deriving coefficients in equation (6). In the current model, an empirical relationship defining the effect of cell temperature and cell current based on active area of the resistance of the cell as developed by Amphlett et al. [5] has been employed

$$
R^{\text {internal }}=0.01605-3.5 \times 10^{-5} T+8.0 \times 10^{-5} i
$$

\subsection{Membrane water flux model}

The activation polarization is defined by the concentration of oxygen at the cathode to membrane interface, which is further dependant upon the water flux in the electrodes and the membrane. As transport in the electrodes is dealt with later in section 3.3, transport within the membrane region is considered here.

By assuming the membrane mixture to be moderately diluted, the flux of a certain species can be obtained as [16]

$$
\dot{n}_{i}=-\frac{D_{\mathrm{i}}}{R T} c_{\mathrm{i}} \nabla \mu_{\mathrm{i}}+v_{\mathrm{j}} c_{\mathrm{i}}
$$

The first term explains that the gradient in chemical potential is the driving force behind migration and diffusion. The second term represents the convection due to the bulk motion of the solvent species. In the case of a membrane under isobaric conditions, it can be reduced to [4]

$$
\dot{n}_{\mathrm{i}}=-\frac{D_{\mathrm{i}}}{R T} c_{\mathrm{i}} \nabla \mu_{\mathrm{i}}
$$


Applying equation (13) to the main water flux in the membrane which flows from cathode to anode, and taking into account the membrane swelling which causes a decrease in the density of the solid membrane gives the main water flux as [4]

$$
\dot{n}_{\mathrm{W}, \mathrm{diff}}=-\frac{\rho_{\mathrm{dry}}}{M_{\mathrm{m}}}\left[D^{\prime} \frac{\lambda}{a(1+s \lambda)^{2}} \frac{\mathrm{d} a}{\mathrm{~d} \lambda}\right] \frac{\mathrm{d} \lambda}{\mathrm{d} z}
$$

The bracket term is the intra-diffusion coefficient of the water in the membrane and can be experimentally obtained as [4]

$$
\begin{aligned}
D_{\lambda>4}= & 10^{-6} \exp \left[2416\left(\frac{1}{303}-\frac{1}{T}\right)\right] \times(2.563-0.33 \lambda \\
& \left.+0.0264 \lambda^{2}-0.000671 \lambda^{3}\right)
\end{aligned}
$$

where $\lambda$ is the water content per membrane charge site. It depends upon the local water vapour activity. At $303 \mathrm{~K}$, it has been experimentally obtained as [4]

$$
\lambda_{303 \mathrm{~K}}=0.043+17.81 a-39.85 a^{2}+36.0 a^{3}
$$

where $a$ is the local water activity and is defined as the ratio of the local water partial pressure to the saturation vapour pressure.

When compared with the main water flux, there is a reverse water flux flowing in the membrane from anode to cathode, which is dragged by the fluxing hydrogen ions. It is therefore a function of the local water content and the flux of hydrogen ions. Experimentally, it is related to the molar flux of hydrogen to the membrane $I$ as [4]

$$
\dot{n}_{\mathrm{W}, \mathrm{drag}}=\frac{5 \lambda}{22} I
$$

Therefore, the net water flux across the membrane is the difference between the main and the dragged water fluxes

$$
\dot{n}_{\mathrm{W}}=\frac{5 \lambda}{22} I-\frac{\rho_{\mathrm{dry}}}{M_{\mathrm{m}}} D_{\lambda} \frac{\mathrm{d} \lambda}{\mathrm{d} z}
$$

To mathematically link the processes of water flux across electrodes to the process of net water flux across membrane, it is necessary to introduce the ratio of net water flux to molar hydrogen flux in the anode, $\alpha_{\mathrm{W}}^{\mathrm{A}}$, into the model. Its value is determined through iteration. Rearranging equation (18) then gives the water distribution in the membrane [4]

$$
\frac{\mathrm{d} \lambda}{\mathrm{d} z}=\frac{M_{\mathrm{m}} I}{\rho_{\text {dry }}} \frac{1}{D_{\lambda}}\left[\frac{5 \lambda}{22}-\alpha_{\mathrm{W}}^{\mathrm{A}}\right]
$$

\section{MULTI-SPECIES TRANSPORTATION MODEL}

Mass transportation characterizes the availability of oxidants and reductants at the catalyst sites, and also the transport of water in and out of the cell.

\subsection{Molar flux of oxidized, reduced, and produced species}

Consider the overall fuel cell reaction $2 \mathrm{H}_{2}+\mathrm{O}_{2} \rightarrow$ $2 \mathrm{H}_{2} \mathrm{O}$. It consists of two electrode processes: the hydrogen oxidation in the active catalyst region of the anode $2 \mathrm{H}_{2} \rightarrow 4 \mathrm{H}^{+}+4 \mathrm{e}^{-}$, and the oxygen reduction process that takes place to produce water in catalyst region of the cathode $\mathrm{O}_{2}+4 \mathrm{H}^{+}$ $+4 \mathrm{e}^{-} \rightarrow 2 \mathrm{H}_{2} \mathrm{O}$.

Assume that there is no crossover of hydrogen fuel through the membrane. Any hydrogen flux through the anode diffuser corresponds exactly to the amount of hydrogen required to induce a constant steady-state cell current density, $J$, through the oxidation process. For the anode

$$
\dot{n}_{\mathrm{H}}^{\mathrm{A}-1}=I=\frac{J}{2 F}
$$

For the cathode, the oxygen flux also corresponds exactly to current flow with zero crossover

$$
\dot{n}_{\mathrm{O}}^{\mathrm{C}-1}=\frac{I}{2}
$$

Define a flux ratio $\alpha_{\mathrm{i}}^{\mathrm{E}}$ of a species i in the electrode E, as the molar flux of species i over the molar flux of oxygen or hydrogen for cathode or anode, denoted as $n$, respectively

$$
\alpha_{\mathrm{i}}^{\mathrm{E}}=\frac{\dot{n}_{\mathrm{i}}^{\mathrm{E}}}{\dot{n}_{\mathrm{n}}^{\mathrm{E}}}
$$

Ideally, the water flux generated, $\dot{n}_{\mathrm{W}}^{\mathrm{Gen}}$, at the cathode equals the molar flux of oxidized hydrogen. The water flux in the cathode is the sum of the water flux from the anode and the water generated by the cell reaction. Therefore, the fluxes of oxidized and reduced species as well as water fluxes can be related as

$$
I=\dot{n}_{\mathrm{H}}^{\mathrm{A}-1}=2 \dot{n}_{\mathrm{O}}^{\mathrm{C}-1}=\dot{n}_{\mathrm{W}}^{\mathrm{Gen}}=\frac{\dot{n}_{\mathrm{W}}^{\mathrm{C}-1}}{1+\alpha_{\mathrm{W}}^{\mathrm{A}}}
$$

In the model, both inlet anode and cathode gas streams have been assumed to be humidified with water up to saturation. The mole fractions of water in the anode and cathode inlet gas streams are given by

$$
y_{\mathrm{W}}^{\mathrm{E}-\mathrm{IN}}=\frac{P_{\mathrm{E}}^{\text {sat }}}{P_{\mathrm{E}}}
$$


The saturation vapour pressure of water is a function of the humidifying temperatures [4]

$$
\begin{aligned}
\log _{10} P_{\mathrm{E}}^{\mathrm{sat}}= & -2.1794+0.02953 T-9.1837 \\
& \times 10^{-5} T^{2}+1.4454 \times 10^{-7} T^{3}
\end{aligned}
$$

When the dry inlet gases each with a species molar fraction of $y_{\mathrm{i}}^{\circ}$ are humidified with a mole fraction of water, $y_{\mathrm{W}}^{\mathrm{E}-\mathrm{IN}}$, the dry mole fractions of the constituent species change, but their ratios relative to hydrogen or oxygen in the anode or cathode, respectively, remain the same

$$
\frac{y_{i}^{\circ}}{y_{\mathrm{n}}^{\circ}}=\frac{y_{\mathrm{i}}^{\mathrm{E}-\mathrm{IN}}}{y_{\mathrm{n}}^{\mathrm{E}-\mathrm{IN}}}
$$

On humidification, the new mole fractions still add up to unity for each electrode

$$
y_{\mathrm{W}}^{\mathrm{E}-\mathrm{IN}}+y_{\mathrm{n}}^{\mathrm{E}-\mathrm{IN}}+\sum_{\mathrm{i}=1}^{\mathrm{n}-1} y_{\mathrm{i}}^{\mathrm{E}-\mathrm{IN}}=1
$$

Rearranging equation (27) and substituting it into equation (26) yields the humidified mole fraction of a species

$$
y_{\mathrm{i}}^{\mathrm{E}-\mathrm{IN}}=y_{\mathrm{i}}^{\circ}\left(1-y_{\mathrm{W}}^{\mathrm{E}-\mathrm{IN}}\right)
$$

For a humidified gas, the ratio of molar flux equals the ratio of mole fractions of different species

$$
\frac{\dot{n}_{\mathrm{i}}^{\mathrm{E}-\mathrm{IN}}}{\dot{n}_{\mathrm{n}}^{\mathrm{E}-\mathrm{IN}}}=\frac{y_{\mathrm{i}}^{\mathrm{E}-\mathrm{IN}}}{y_{\mathrm{n}}^{\mathrm{E}-\mathrm{IN}}}
$$

The water fluxes across the electrodes can then obtained as

$$
\dot{n}_{\mathrm{W}}^{\mathrm{E}-\mathrm{IN}}=\dot{n}_{\mathrm{n}}^{\mathrm{E}-\mathrm{IN}} \frac{y_{\mathrm{W}}^{\mathrm{E}-\mathrm{IN}}}{y_{\mathrm{n}}^{\circ}\left(1-y_{\mathrm{W}}^{\mathrm{E}-\mathrm{IN}}\right)}
$$

and for any other species i

$$
\dot{n}_{\mathrm{i}}^{\mathrm{E}-\mathrm{IN}}=\dot{n}_{\mathrm{n}}^{\mathrm{E}-\mathrm{IN}} \frac{y_{\mathrm{i}}^{\circ}}{y_{\mathrm{n}}{ }^{\circ}}
$$

Define the stoichiometric ratios as the ratio of the oxidant or the reductant flux in the inlet to the flux of oxidant or reductant corresponding to the hydrogen flux to the membrane $\varphi_{\mathrm{H}}=\left(\dot{n}_{\mathrm{H}}^{\mathrm{A}-\mathrm{IN}}\right) / I$ for the anode, and $\varphi_{\mathrm{O}}=\left(\dot{n}_{\mathrm{O}}^{\mathrm{C}-\mathrm{IN}}\right) /(I / 2)$ for the cathode. The inlet flux of species i to the anode is

$$
\dot{n}_{\mathrm{i}}^{\mathrm{A}-\mathrm{IN}}=I \varphi_{\mathrm{H}} \frac{y_{\mathrm{i}}^{\circ}}{y_{\mathrm{H}}^{\circ}}
$$

and to the cathode

$$
\dot{n}_{\mathrm{i}}^{\mathrm{C}-\mathrm{IN}}=\frac{1}{2} I \varphi_{\mathrm{O}} \frac{y_{\mathrm{i}}^{\circ}}{y_{\mathrm{O}}^{\circ}}
$$

\subsection{Channel flows}

The inlet flux of a species to either anode or cathode constitutes towards the species flux in the channel and the species flux through the electrode

$$
\dot{n}_{\mathrm{i}}^{\mathrm{E}-\mathrm{IN}}=\dot{n}_{\mathrm{i}}^{\mathrm{E}-\mathrm{CH}}+\dot{n}_{\mathrm{i}}^{\mathrm{E}-1}
$$

Substituting equation (22) and equation (32) or (33) into equation (34), gives the species flux in the anode

$$
\dot{n}_{\mathrm{i}}^{\mathrm{A}-\mathrm{CH}}=I\left(\varphi_{\mathrm{H}} \frac{y_{\mathrm{i}}^{\circ}}{y_{\mathrm{H}}^{\circ}}-\alpha_{\mathrm{i}}^{\mathrm{A}}\right)
$$

and in the cathode channel as

$$
\dot{n}_{\mathrm{i}}^{\mathrm{C}-\mathrm{CH}}=I\left(\frac{\varphi_{\mathrm{H}}}{2} \frac{y_{\mathrm{i}}^{\circ}}{y_{\mathrm{H}}^{\circ}}-\alpha_{\mathrm{i}}^{\mathrm{C}}\right)
$$

The total channel flux is the sum of all species fluxes including water, plus any additional flux of foreign species from the opposite electrode (OE)

$$
\dot{n}_{\text {total }}^{\mathrm{E}-\mathrm{CH}}=\dot{n}_{\mathrm{W}}^{\mathrm{E}-\mathrm{CH}}+\sum_{\mathrm{i}=1}^{\mathrm{n}} \dot{n}_{\mathrm{i}}^{\mathrm{E}-\mathrm{CH}}+\sum_{\mathrm{i}=1}^{\mathrm{n}_{\mathrm{OE}}} \dot{n}_{\mathrm{i}}^{\mathrm{OE}-1}
$$

In the current model, if an inert species is assumed not to permeate the membrane, the flux ratios of this species can be reduced to zero, i.e. $\alpha_{\mathrm{i}}^{\mathrm{A}}=0$ or $\alpha_{\mathrm{i}}^{\mathrm{C}}=0$, which reduces the additional flux from the opposite.

The species mole fraction in the channel can be obtained as

$$
y_{\mathrm{i}}^{\mathrm{E}-\mathrm{CH}}=\frac{\dot{n}_{\mathrm{i}}^{\mathrm{E}-\mathrm{CH}}}{\dot{n}_{\mathrm{total}}^{\mathrm{E}-\mathrm{CH}}}
$$

\subsection{Gas transportation in the electrode diffusion layer}

It is expected that a gradient in mole fraction exists across the electrode diffusion layer for all species, although the flux of inert species may not be zero. Diffusion in the electrode diffuse layers is described by the Stefan-Maxwell equation in the model

$$
\frac{\mathrm{d} y_{\mathrm{i}}^{\mathrm{E}}}{\mathrm{d} z}=R T \sum_{\mathrm{i}} \frac{y_{\mathrm{i}}^{\mathrm{E}} \dot{n}_{\mathrm{j}}^{\mathrm{E}-1}-y_{\mathrm{j}}^{\mathrm{E}} \dot{n}_{\mathrm{i}}^{\mathrm{E}-1}}{P D_{\mathrm{ij}}}
$$


The species mole fraction at the electrode to membrane interface can be obtained by integrating the equation across the electrode using channel mole fractions.

The pressure-diffusivity term for species pair i and $\mathrm{j}$ in the equation was defined using the Slattery-Bird equation [17]

$$
P D_{\mathrm{ij}}=a\left(\frac{T}{T_{\mathrm{c}, \mathrm{j}}}\right)^{b}\left(M_{\mathrm{ij}}\right)^{-1 / 2}\left(P_{\mathrm{c}, \mathrm{jj}}\right)^{2 / 3}\left(T_{\mathrm{c}, \mathrm{ij}}\right)^{5 / 6}
$$

where $\quad M_{\mathrm{ij}}=\left(2 M_{\mathrm{i}} M_{\mathrm{j}} /\left(M_{\mathrm{i}}+M_{\mathrm{j}}\right)\right) \times T_{\mathrm{c}, \mathrm{ij}}=\left(T_{\mathrm{c}, \mathrm{i}} T_{\mathrm{c}, \mathrm{j}}\right)^{1 / 2}$ and $P_{\mathrm{c}, \mathrm{ij}}=\left(P_{\mathrm{c}, \mathrm{i}} P_{\mathrm{c}, \mathrm{j}}\right)^{1 / 2}$ are the critical properties of the constituent species.

The pressure-diffusivity product is further modified by the Bruggeman correction factor $\varepsilon^{3 / 2}$ to account for porosity in the electrodes [4] in the model.

\subsection{Gas transportation in the membrane}

To simulate a gas species permeating through the membrane, it is assumed that a diffusive flux of the species across the membrane is driven by a concentration gradient. Fick's law of diffusion [18] is therefore applied to describe this flux. CO has serious degradation effect on electrode's catalysts. Its flux is simulated in the model using the binary diffusivity $D_{\mathrm{CO}-\mathrm{H}_{2} \mathrm{O}}$ of $\mathrm{CO}$ and water. Applying equation (22) to Fick's law, the flux ratio of $\mathrm{CO}$ to $\mathrm{H}_{2}$ in the anode is given as

$$
\alpha_{\mathrm{CO}}^{\mathrm{A}}=-\frac{P D_{\mathrm{CO}-\mathrm{H}_{2} \mathrm{O}}}{R T} \frac{1}{\dot{n}_{\mathrm{H}_{2}}^{\mathrm{A}}} \nabla y_{\mathrm{CO}}
$$

The variable $\alpha_{\mathrm{CO}}^{\mathrm{A}}$ is refined via iteration. The correct value is obtained when the $\mathrm{CO}$ mole fraction at cathode to membrane interface calculated from membrane side using equation (41) equals the CO mole fraction calculated from cathode side using equation (39).

\subsection{Semi-empirical CO degradation effect}

Although it has received little attention, CO is known to permeate through the membrane and to consequently degrade the performance of the cathode catalyst layer [13]. Using the model of CO transportation in the membrane, the effect on cathode performance is simulated in the model by using a CO induced degradation factor, $\Theta$, defined as

$$
\Theta=\frac{\eta_{\mathrm{act}, \text { cath }}^{\text {pure }}-\eta_{\text {act,cath }}^{\text {pois }}}{\eta_{\text {act,cath }}^{\text {pure }}}
$$

where $\eta_{\text {act,cath }}^{\text {pure }}$ is the cathodic activation polarization with pure hydrogen and $\eta_{\text {act,cath }}^{\text {pois }}$ is the activation polarization with CO contamination.
In a previous experimental study by Qi et al. [13], the cathode potential was measured using three different anode feeds: pure $\mathrm{H}_{2}, 70$ per cent $\mathrm{H}_{2}$ plus 30 per cent $\mathrm{CO}_{2}$ with $10 \mathrm{ppm} \mathrm{CO}$, and 70 per cent $\mathrm{H}_{2}$ plus 30 per cent $\mathrm{CO}_{2}$ with 50 ppm CO. The cathode potential reflects the sum of the thermodynamic equilibrium potential, the ohmic polarization, and the cathodic activation polarization. The thermodynamic equilibrium potential and the ohmic polarization are not functions of $\mathrm{CO}$ contamination. They can be calculated and taken away from the measured value to obtain the cathode activation polarization.

The CO induced degradation factor is assumed to be a linear function of the interfacial CO concentration at any given current density. This is simply due to the fact that the experimental data covered two contaminated fuel feeds only. The first tested fuel was pure $\mathrm{H}_{2}$ and was only used to determine the cathodic activation polarization $\eta_{\text {act,cath }}^{\text {pure }}$. However, it cannot be used to determine the degradation factor. This is because the $\mathrm{CO}_{2}$ contained in the fuel feed could have some degradation effect on cathode performance due to the water-gas shift reaction at the anode [19]. Such effect in the model is assumed to be constant for any given current density and independent of the CO transport due to fuel feed CO contamination. The relationship between the cathode-membrane interfacial $\mathrm{CO}$ concentration and the degradation factor was modelled as

$$
\Theta=\Theta_{0}+H y_{\mathrm{CO}}^{\prime \mathrm{C}-2}
$$

where $\Theta_{0}$ is the water-gas shift induced degradation factor, $y_{\mathrm{CO}}^{\prime \mathrm{C}-2}$ is the $\mathrm{CO}$ concentration at cathode to membrane interface in ppm, and $H$ is the gradient of the change in degradation factor with respect to the change in CO interfacial concentration.

The gradient $H$ is obtained from the experimental data [13]. It is found to be non-linear with respect to current density as shown in Fig. 2. The polynomial fit of equation (44) was deduced

$$
\begin{aligned}
H= & -0.2056 J^{3}+0.3956 J^{2}-0.1194 J \\
& +0.0430
\end{aligned}
$$

For the straight-line relationship postulated in equation (43), the $\mathrm{CO}$ degradation factor attributable to the water-gas shift reaction $\Theta_{0}$ is derived from the published results [13] and is shown in Fig. 3. Again, it is found to be non-linear with respect to current density, and the polynomial fit is given in equation (45)

$$
\begin{aligned}
\Theta_{0}= & 0.4551 J^{4}-1.1161 J^{3}+1.2495 J^{2} \\
& -0.6145 J+0.11
\end{aligned}
$$




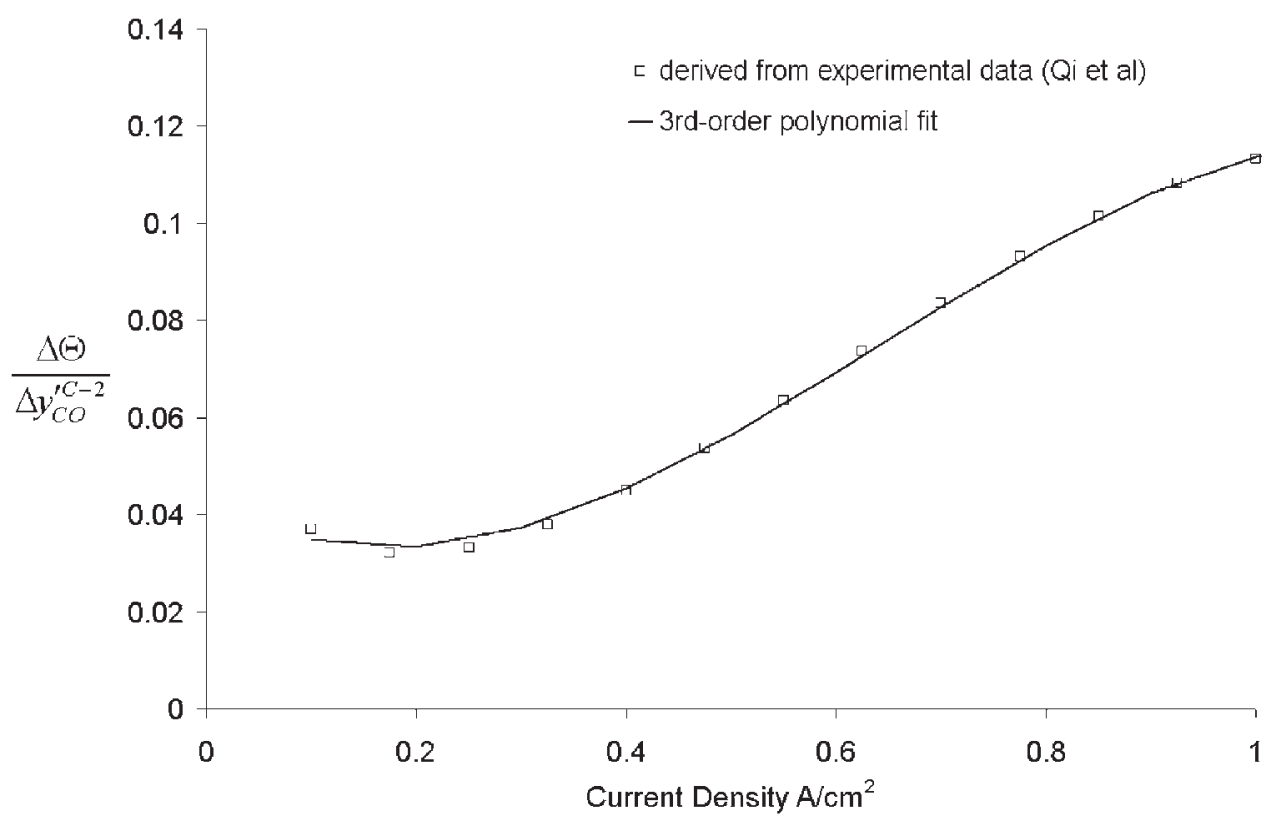

Fig. 2 Third-order polynomial dependence of $H$ on current density $J$

The total activation polarization given in equation (7) includes both anode and cathode activation polarization, and cannot be decomposed into individual contributions. To solely simulate the cathode activation overpotential with a pure $\mathrm{H}_{2}$ fuel feed, the Tafel equation derived from equation (3) was employed

$$
\eta_{\text {act,cath }}^{\text {pure }}=\frac{R T}{0.5 F} \ln \left(\frac{j_{0}}{J}\right)
$$

where the exchange current density $j_{0}$ was estimated to be $0.8 \times 10^{-3} \mathrm{~A} / \mathrm{cm}^{2}$ for the cell from the experimental data obtained by Qi et al. [13].

For a 70 per cent $\mathrm{H}_{2}$ plus 30 per cent $\mathrm{CO}_{2}$ prehumidified fuel feed with any level of CO contamination, the cathodic activation polarisation is

$$
\eta_{\text {act,cath }}^{\text {pois }}=\eta_{\text {act,cath }}^{\text {pure }}(1+\Theta)
$$

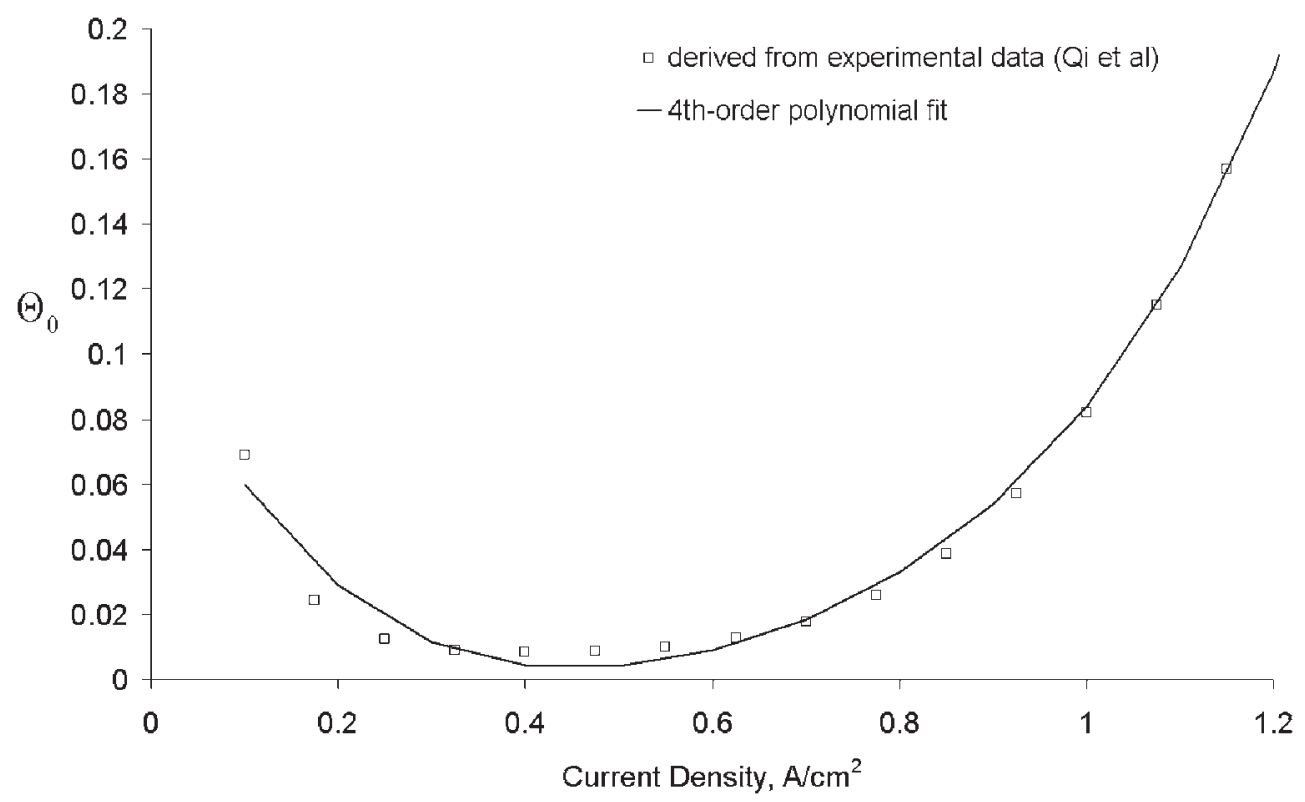

Fig. 3 Fourth-order polynomial dependence of $\Theta_{0}$ on current density $J$ 


\section{RESULTS AND DISCUSSION}

\subsection{Polarization}

Figure 4 shows a comparison of calculated cell voltage at varying current density with experimental results obtained from the Ballard Mark IV [5]. The cell conditions during the test and the inputs into the model were air with 21 per cent of $\mathrm{O}_{2}$ and 79 per cent of $\mathrm{N}_{2}$, pure hydrogen fuel supply, $343 \mathrm{~K}$ operating temperature, and $310 \mathrm{kPa}$ operation pressure. The porosity was 0.3 , and the thickness was $250 \mu \mathrm{m}$ for both electrodes. Oxygen stoichiometry was set to 1.75 and hydrogen stoichiometry set to 1.3. The membrane thickness was $180 \mu \mathrm{m}$, the dry membrane density was assumed to be $1.98 \mathrm{~g} / \mathrm{cm}^{3}$, and its equivalent weight was $1100 \mathrm{~g} / \mathrm{mol}$. The active cell area was given as $50.56 \mathrm{~cm}^{2}$.

The results show that the model prediction agrees well with the experimental results despite the region at higher current densities. In the current model, the thermal gradients were not included, which invariably exist in the cell. Any drying effects in the membrane reduce its conductivity and increase ohmic polarization thereby reducing the cell output voltage. This drying effect is likely to be observed at higher current densities.

Figure 5 shows the measured and calculated effects of varying oxygen composition at 21, 46, and 100 per cent on the cell voltage. The results show that the cell voltage decreases as oxygen composition reduces. This is because the activation polarization, which is dominated by cell operation temperature, current density, and oxygen concentration at the membrane to cathode interface, decreases as the availability of oxygen in the supply increases. Such effect has been included in equation (9).

Figure 6 shows the measured and calculated effects of different cell operation temperatures on the cell voltage at varying current density. The figure shows that the cell voltage increases as temperature increases. The reason of such increase is largely due to the fact that both cell internal electric resistance and activation polarization are dependant on cell operation temperature as shown in equations (7) and (11), respectively. As cell operation temperature increases, both internal electric resistance and activation polarization decrease.

It is interesting to address that there is a noticeable discrepancy between simulated and measured results at the operation temperature of $358 \mathrm{~K}$. The simulated cell voltage is lower than the measured value. This may be due to the fact that although a saturated inlet gas has been used in the model during the test, the same condition may have been difficult to maintain at the high humidifying temperature $[\mathbf{2 0}]$. The saturation, hence the relative humidity, has a significant influence towards interfacial oxygen mole fractions and cell activation polarization. Figure 7 shows the simulated interfacial oxygen mole fractions with 50 and 100 per cent of saturating vapour pressure at $358 \mathrm{~K}$ in the cathode inlet stream. It shows that the oxygen molar fraction at the cathode to membrane interface increases as humidity decreases. Figure 8 shows the calculated cell activation polarization at varying current densities with 50 and 100 per cent of saturation

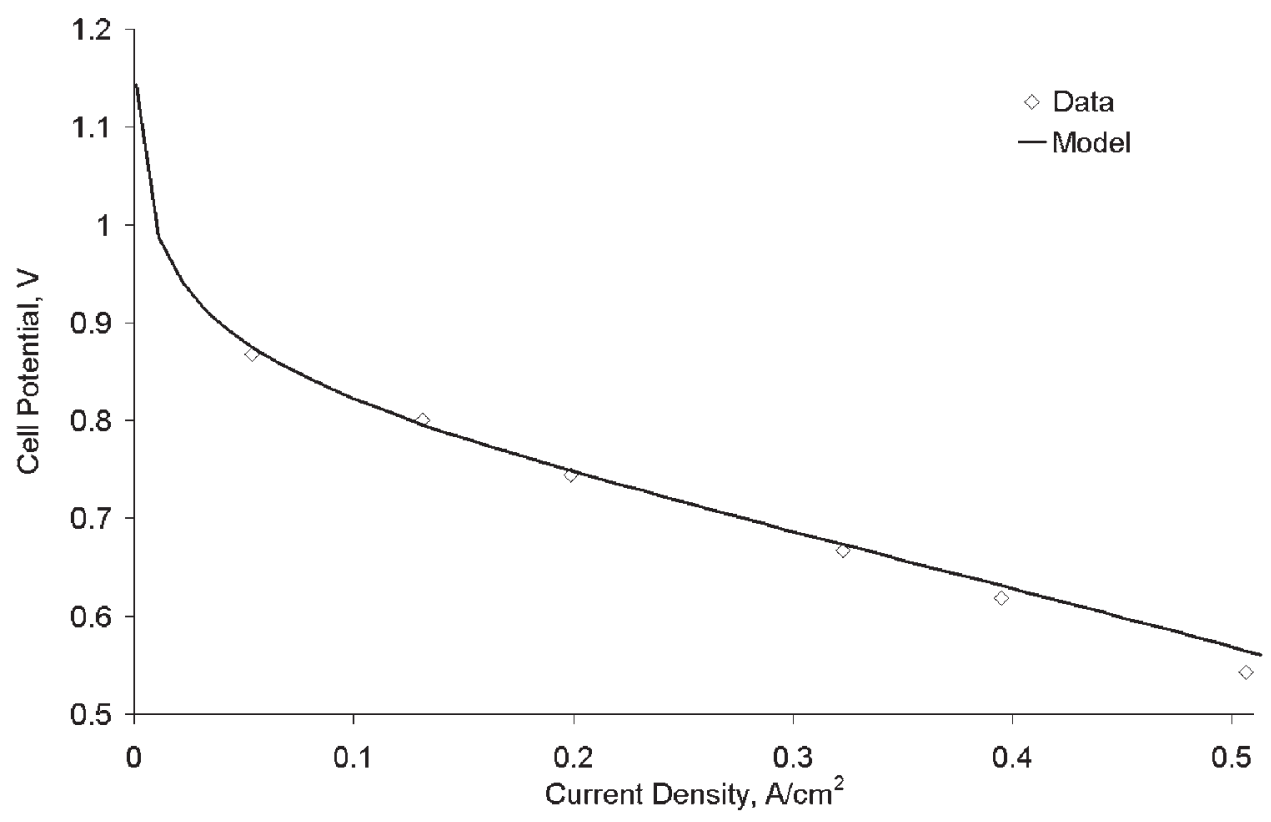

Fig. 4 Simulated and measured fuel cell performance 


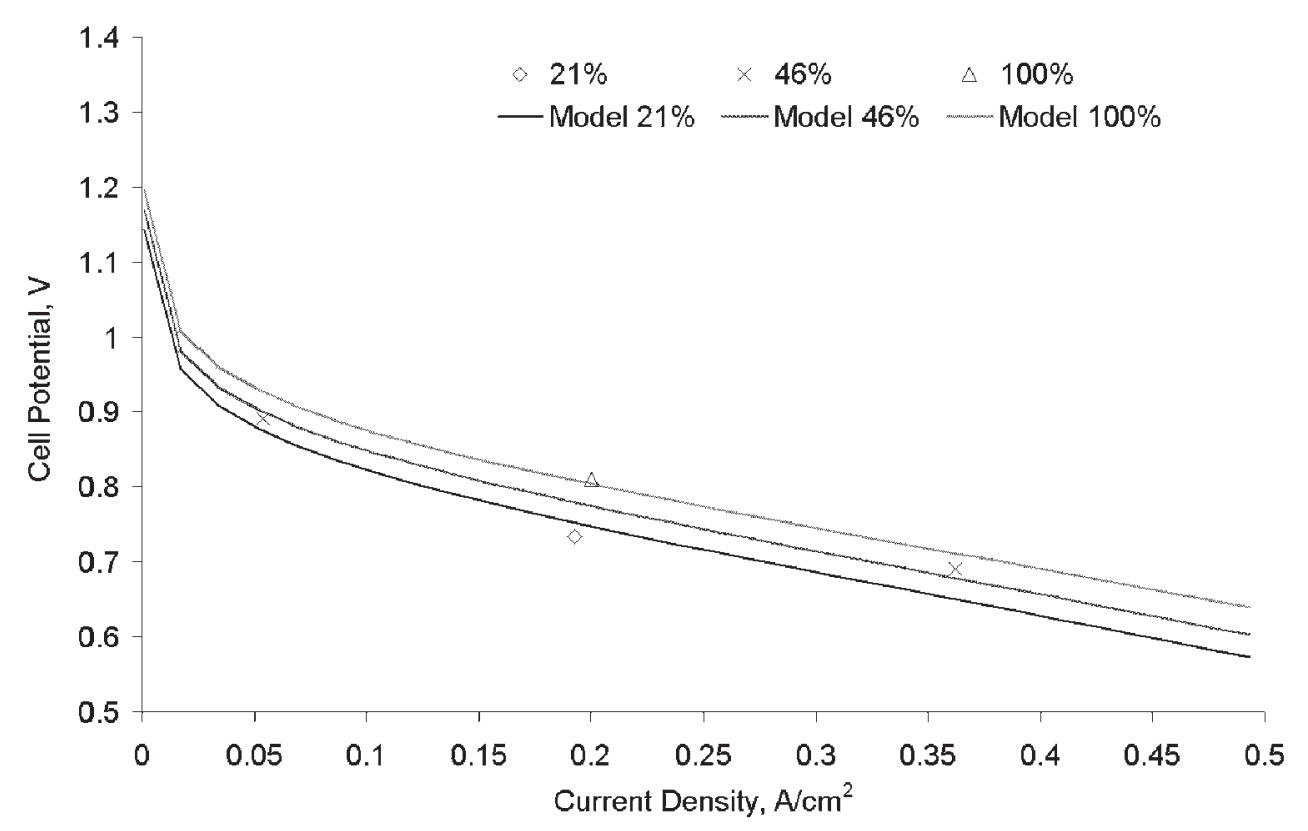

Fig. 5 Effects of varying oxygen composition on the fuel cell performance

pressure achieved at $358 \mathrm{~K}$. The figure shows that the absolute value of cell activation polarization increases as humidification increases. In other words, the effect of less humidification is to decrease the impact of activation polarization alone on the thermodynamic cell voltage.

We may then compare the simulated cell voltage under this condition with that obtained from the test. Figure 9 shows the comparison between the measured and the recalculated polarization curve. Comparing with the discrepancy in the previous result shown in Fig. 6, the agreement at 50 per cent of saturation pressure is noticeably better.

Figure 10 shows the effects of varying hydrogen composition, 65, 81, and 100 per cent on cell voltage. Similar to the effect of oxygen variation, the cell voltage decreases as hydrogen composition reduces. This is due to two reasons. First, the thermodynamic equilibrium potential is modelled as a directly proportional function of the square of

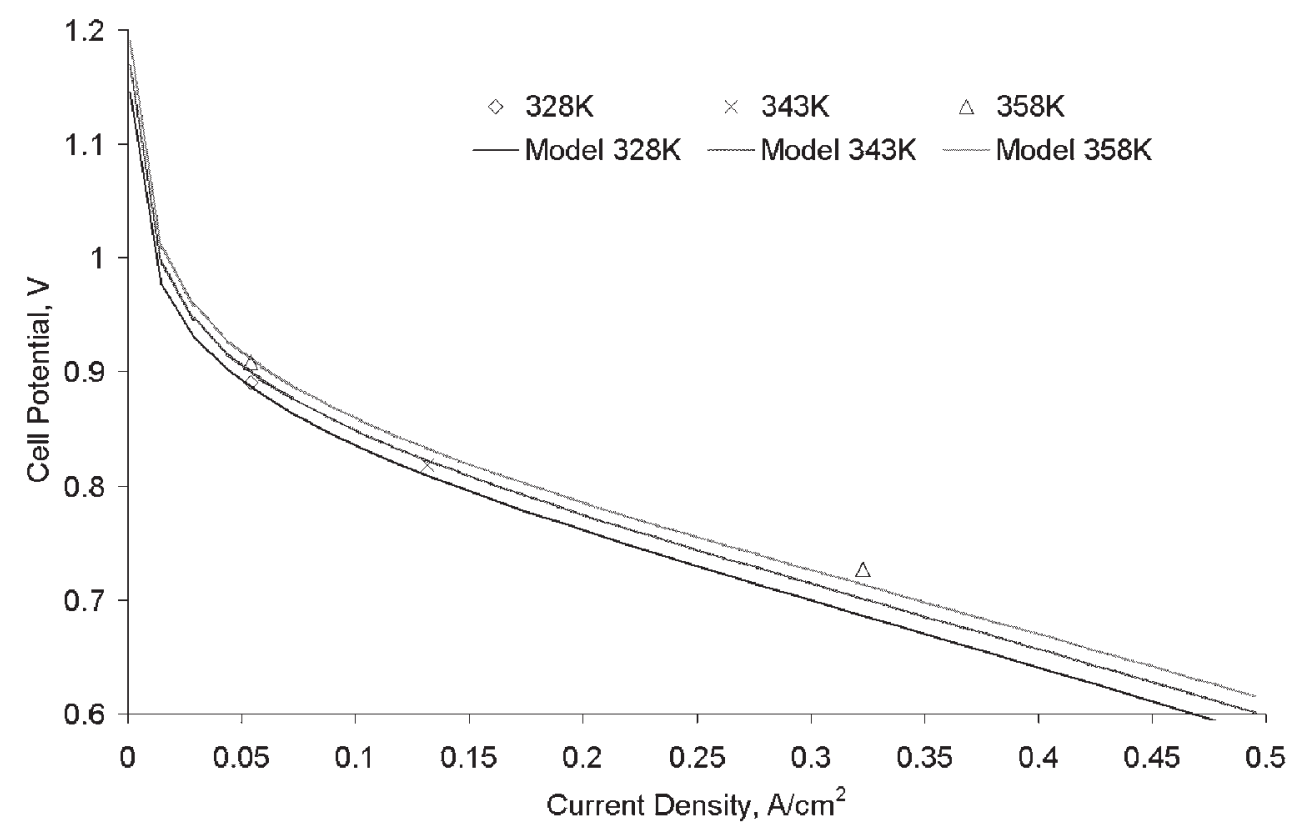

Fig. 6 Effects of varying temperature on the fuel cell performance 


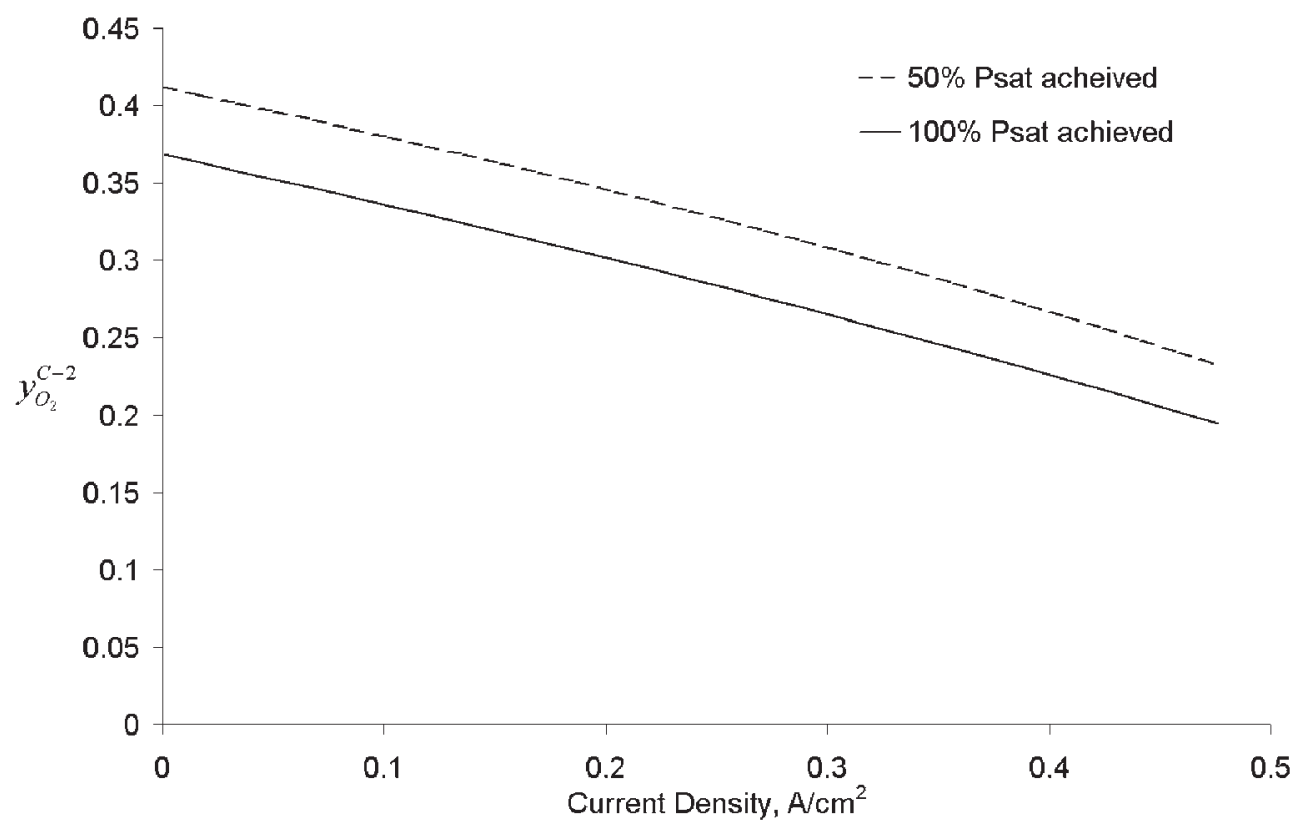

Fig. 7 Interfacial oxygen mole fractions with 50 and 100 per cent saturation at $358 \mathrm{~K}$

the hydrogen partial pressure. Correspondingly, any increase in the hydrogen inlet composition results in an increase of the thermodynamic equilibrium. This is because the hydrogen mole fraction gradient is positive through the electrode thickness leading to higher interfacial values. The limited overall impact on cell performance is attributed to the fact that anodic activation is modelled as a constant in the empirical equation for activation polarization. Increasing interfacial hydrogen partial pressure would induce no change in equation (7).

Furthermore, the activation polarization for hydrogen oxidation at $298.15 \mathrm{~K}$ and at a current density of $0.1076 \mathrm{~A} / \mathrm{cm}^{2}$ is $0.009 \mathrm{~V}$ compared with $0.35 \mathrm{~V}$ for oxygen reduction [5]. This, therefore, illustrates that the total activation polarization is largely characterized by the cathodic oxygen reduction, which is slower than the anodic hydrogen oxidation process. The implication of the relative

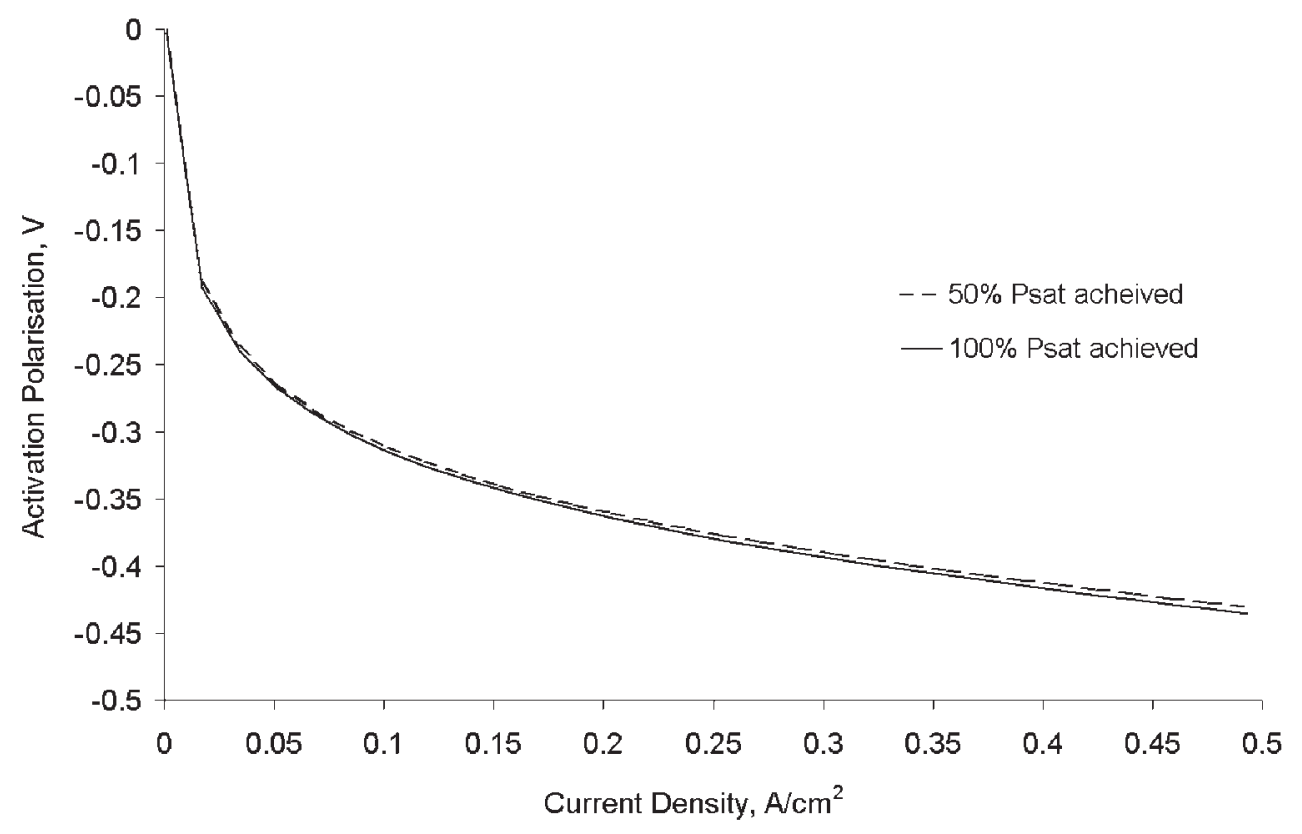

Fig. 8 Activation polarization with 50 and 100 per cent of saturation at $358 \mathrm{~K}$ 


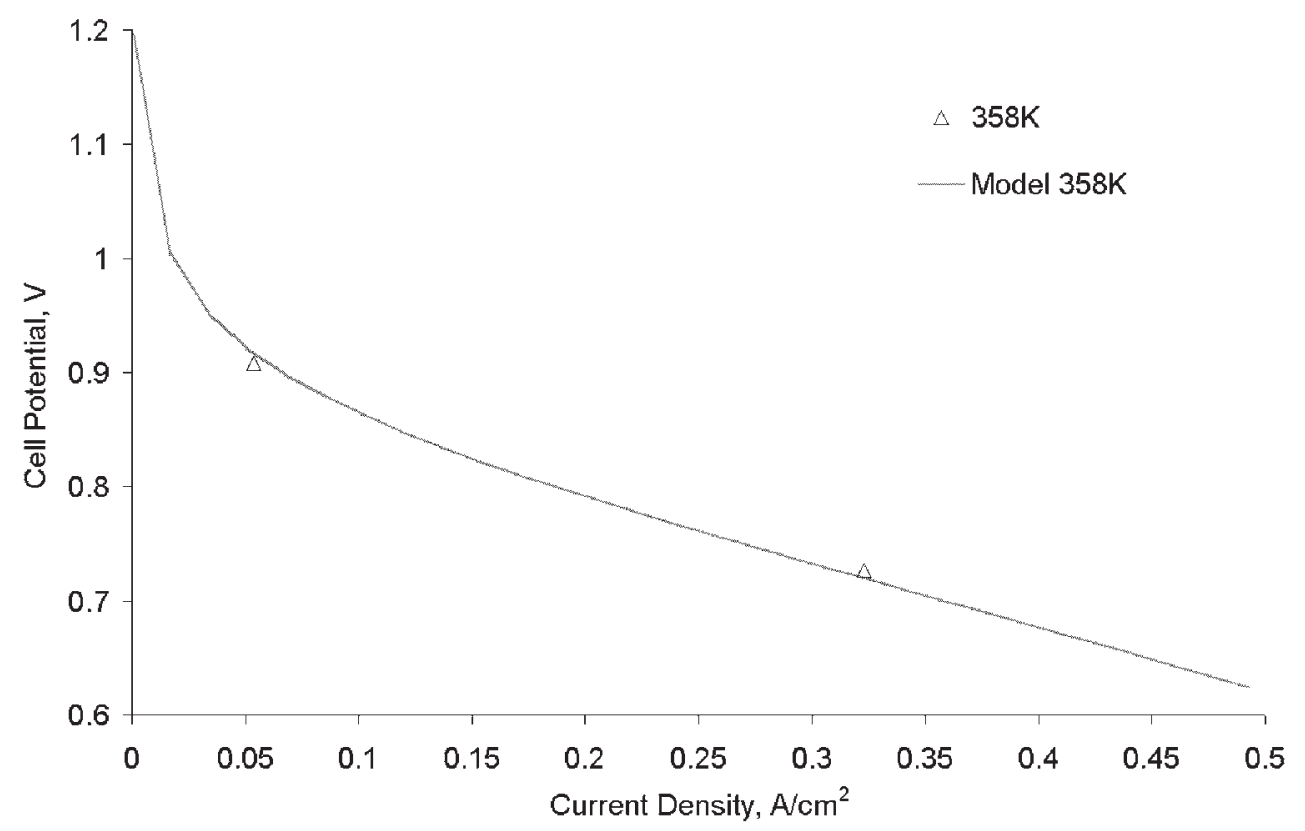

Fig. 9 Effect of oxygen mole fraction on the fuel cell voltage

insignificance of anodic activation polarization due to fast electrode kinetics is that the assumption of constant anodic activation polarization implied in equation (7) is valid in the current density range of interest in Fig. 8.

\subsection{Multi-component diffusion}

Experimental research on transient performance published by Moore et al. [21] indicated that the atmospheric concentrations of benzene could degrade cell performance. A $30 \mathrm{~min}$ exposure to air containing $50 \mathrm{ppm}$ of benzene showed irreversible losses in cell performance. Furthermore, it has been suggested that prolonged exposure to atmospheric concentrations of nitrogen dioxide and sulphur dioxide could also degrade the cell performance. Figure 11 shows some of the calculated cathode to membrane interfacial mole fractions at varying current density when the cell is supplied

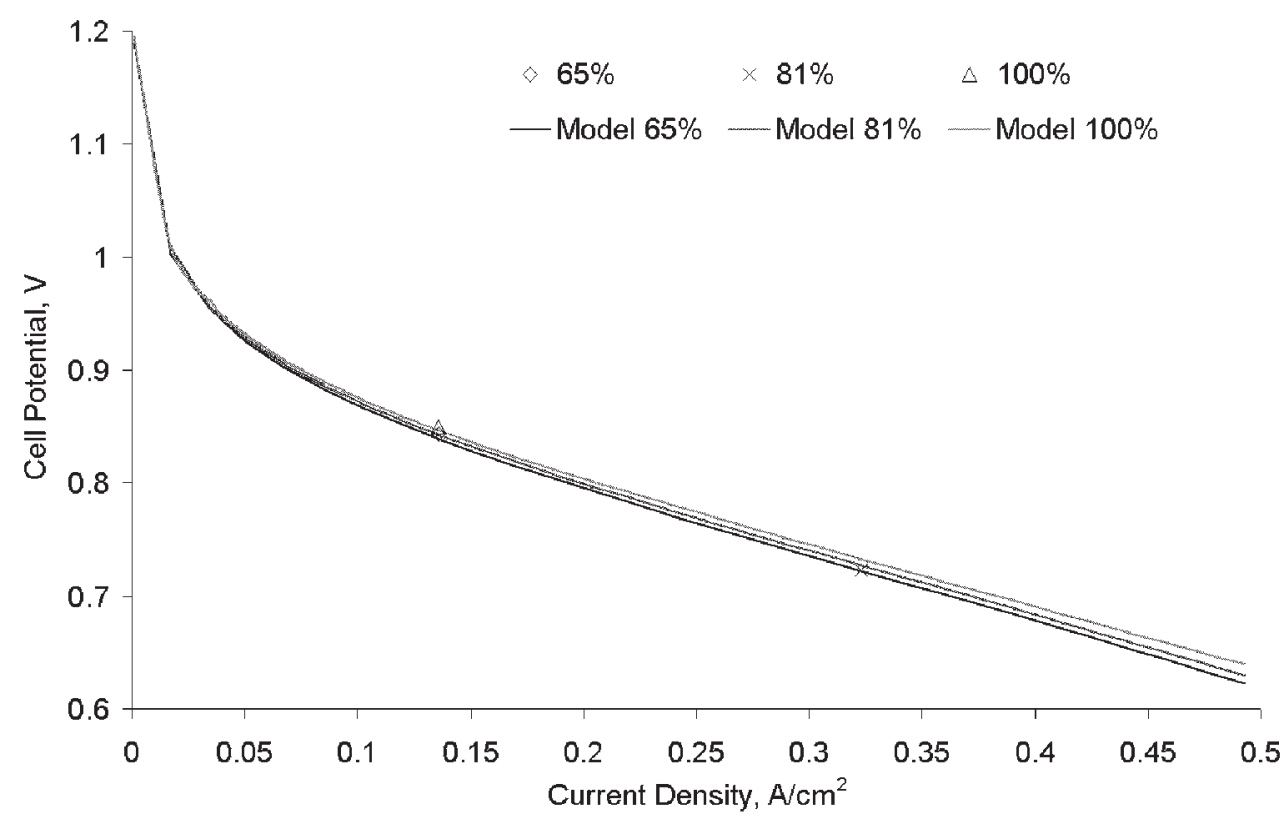

Fig. 10 Effects of varying hydrogen composition on the fuel cell performance 


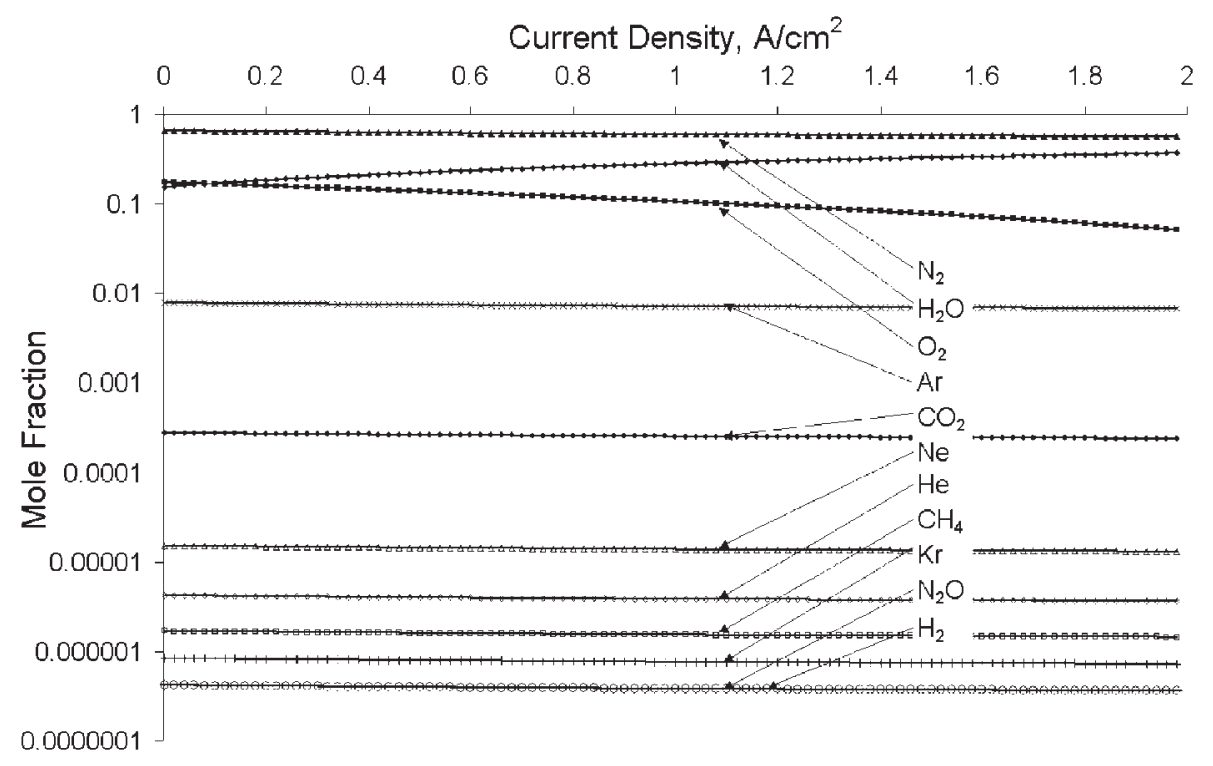

Fig. 11 Interfacial air constituent mole fractions at cathode-membrane interface

with clean, dry air which contains $\mathrm{O}_{2}, \mathrm{~N}_{2}, \mathrm{Ar}, \mathrm{CO}_{2}, \mathrm{Ne}$, $\mathrm{He}, \mathrm{Kr}, \mathrm{CH}_{4}, \mathrm{H}_{2}$, and $\mathrm{N}_{2} \mathrm{O}$ at the cathode inlet. It shows that the multi-component diffusion model has the potential to take almost all chemical constituents in the atmosphere into account simultaneously.

\subsection{CO crossover and contamination}

Figure 12 shows the calculated cathode potential for fuel feeds with different inlet CO concentrations and the experimental results obtained by Qi et al. [13]. Both predictions and experimental results were based on a thin $25-\mu \mathrm{m}$ thick membrane. The anode catalyst was a platinum-ruthenium alloy applied with a loading of $0.6 \mathrm{mg} / \mathrm{cm}^{2}$. The cathode catalyst was pure platinum applied with a loading of $0.4 \mathrm{mg} / \mathrm{cm}^{2}$. The simulated and measured results agree well with pre-humidified fuel feeds of pure $\mathrm{H}_{2}, \mathrm{H}_{2}$ mixed with 30 per cent $\mathrm{CO}_{2}$ and 10 ppm $\mathrm{CO}$, and $50 \mathrm{ppm}$ CO. Model predictions with high $\mathrm{CO}$ concentrations in the fuel feed are also presented

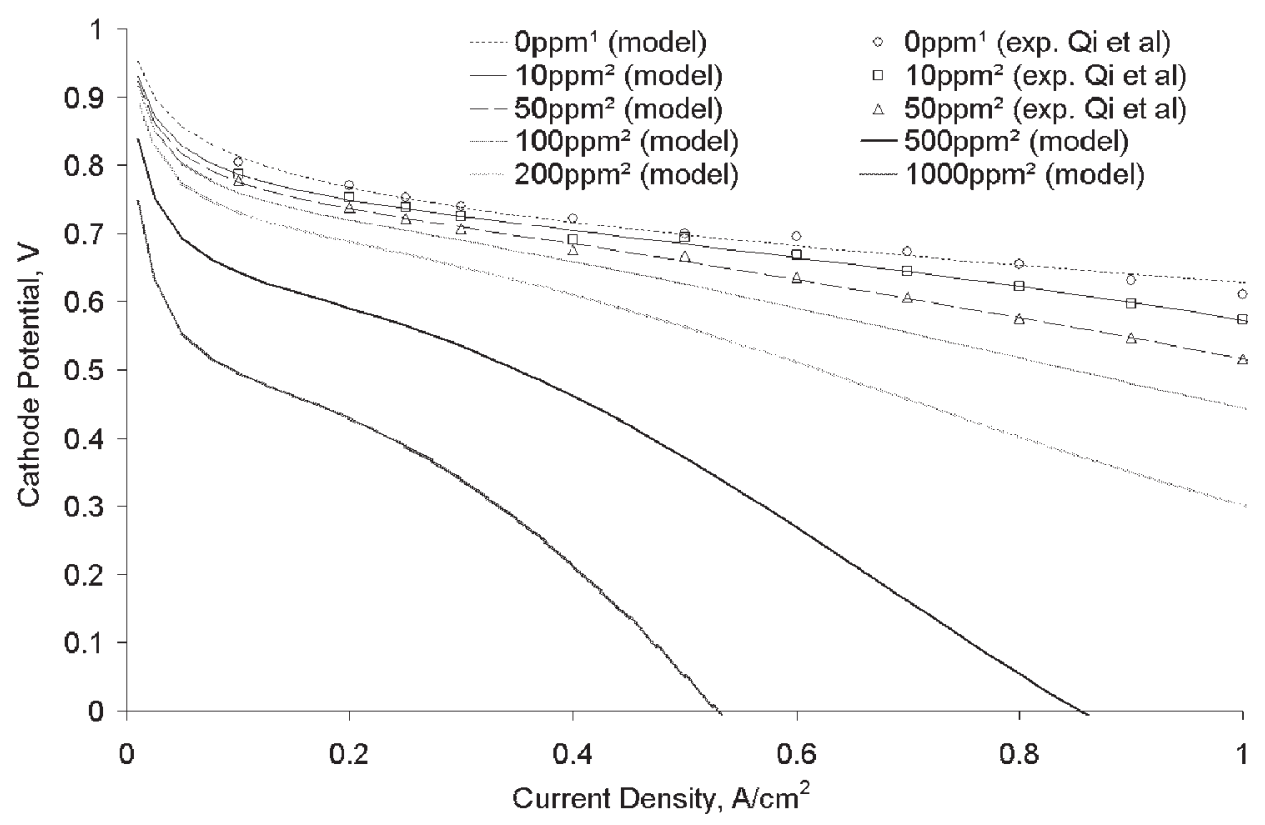

Fig. $12 \mathrm{CO}$ crossover effects on cathode potential. (1) Pure $\mathrm{H}_{2}$ pre-humidified fuel feed; (2) 30 per cent $\mathrm{CO}_{2} / 70$ per cent $\mathrm{H}_{2}$ pre-humidified fuel feed 
in the figure. The cathode is supplied with a prehumidified air containing 21 per cent $\mathrm{O}_{2}$ and 79 per cent $\mathrm{N}_{2}$. It shows the significant losses on the cathode potential with fuel feeds contaminated with high CO concentrations.

The simulation results showed that the CO concentration at the cathode-membrane interface does not vary significantly with respect to current density. The interfacial CO concentration at $1.5 \mathrm{~A} / \mathrm{cm}^{2}$ is $298 \mathrm{ppb}$. This is less than a 0.5 per cent increase compared with $0.01 \mathrm{~A} / \mathrm{cm}^{2}$ when the fuel feed is contaminated with $10 \mathrm{ppm}$ of $\mathrm{CO}$. The small increase in $\mathrm{CO}$ interfacial concentration is due to the fact that the $\mathrm{CO}$ flux in the anode and membrane is at least two orders of magnitude smaller than $\mathrm{H}_{2}$ flux at a current density of $0.1 \mathrm{~A} / \mathrm{cm}^{2}$ and up to three orders of magnitude smaller at higher current densities. This is shown in Fig. 13 where the change in the ratio of $\mathrm{CO}$ to $\mathrm{H}_{2}$ flux in the anode and membrane $\alpha_{\mathrm{CO}}^{\mathrm{A}}$ with respect to current density is presented.

The experimental results obtained by Qi et al. [13] showed that the anode overpotential was linear and relatively smaller in relation to the cathode potential. The cathode potential therefore closely characterizes the cell potential. Oetjen et al. [22], for example, investigated the effect of $\mathrm{CO}$ poisoning on the overall cell potential with $\mathrm{H}_{2}$ feeds contaminated up to $250 \mathrm{ppm}$ of CO. The experimental results for an anode loaded with platinum-ruthenium catalyst exhibited the similar linear current density to polarization relationships above $0.2 \mathrm{~A} / \mathrm{cm}^{2}$ as those presented in Fig. 12. However, the polarizations predicted by the model in Fig. 12 are generally lower than the experimental results. This may partially be attributed to the differences in catalytic loading, fuel feed, and oxidant supply. The cathode and anode catalysts loadings were $1 \mathrm{mg} / \mathrm{cm}^{2}$ of pure platinum and platinum-ruthenium, respectively. This is 150 and 67 per cent higher than the catalyst loadings used in the experiments and cited by the model. In addition, Oetjen et al. [22] did not use fuel feeds containing $\mathrm{CO}_{2}$ and the cathode feed was pure oxygen. Both conditions would serve to increase the availability of hydrogen and oxygen at the anode and cathode catalyst sites, respectively, and reduce the activation overpotentials.

\section{CONCLUSIONS}

A 1D steady-state, low temperature, isothermal, isobaric PEMFC model has been developed. The model accommodates multi-component diffusion in the porous electrodes and therefore offers the potential to further investigate effects of some 'inert gases' on cell performances. In this model

- the channel flows were determined using mass balance and algebraic manipulation and derived from predefined initial inlet conditions;

- the electrode fluxes are determined by hydrogen oxidation and oxygen reduction with zero crossover;

- the gas diffusion through the electrodes is modelled using the Stefan-Maxwell equation;

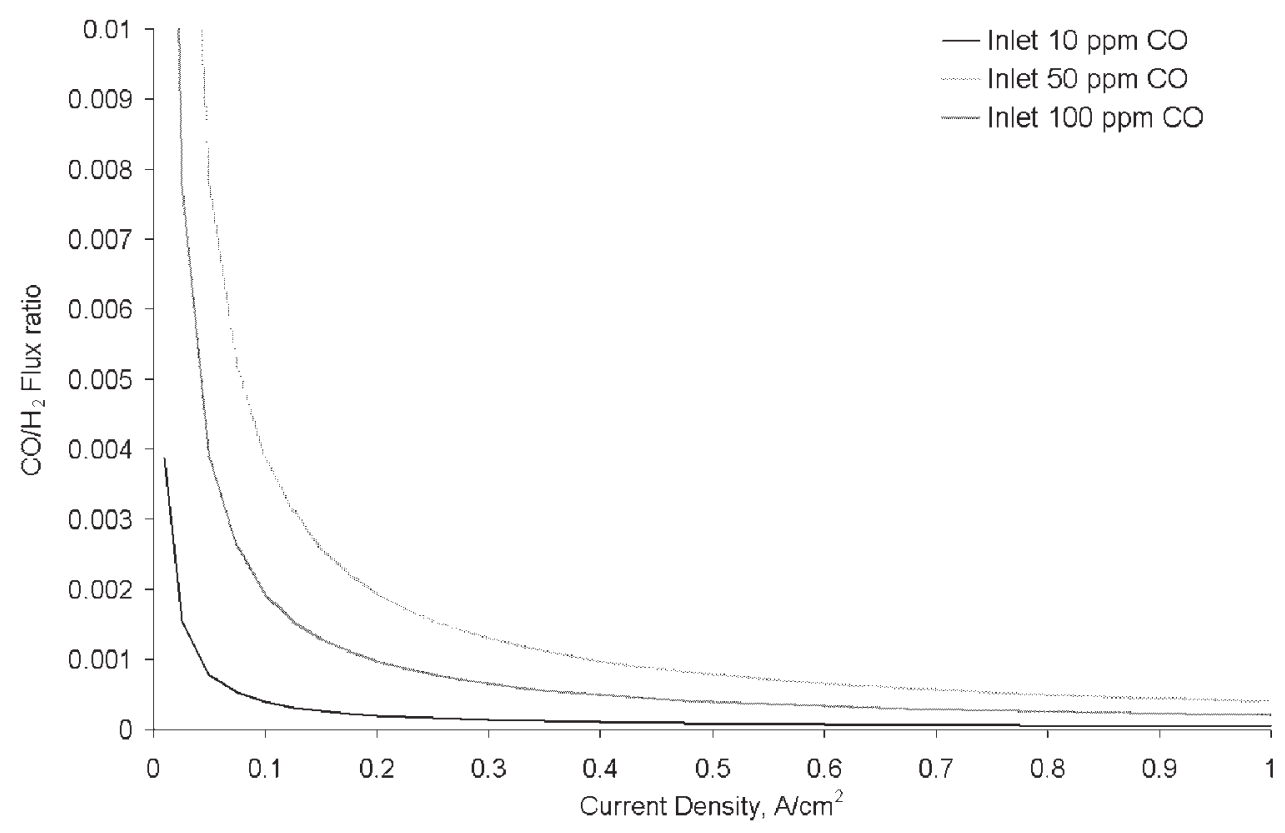

Fig. $13 \mathrm{CO}$ to $\mathrm{H}_{2}$ flux ratio for inlet fuel feed CO concentrations of 10, 50, and $100 \mathrm{ppm}$ 
- the catalyst layers were considered as fine dispersion of platinum and platinum-ruthenium at the cathode-membrane and anode-membrane interfaces;

- electrode kinetics have been described using the Butler-Volmer equation. The treatment of electrode surface kinetics pertains to Berger's suggestion that oxygen reduction and hydrogen chemisorption are the rate controlling steps for activation [15];

- the membrane transportation in the model considered the water flux in the membrane due to both diffusion and water dragging because of hydrogen-ion flux as developed by Springer et al. [4];

- semi-empirical expressions developed by Amphlett et al. [5] has been adopted in the model to simulate the loss mechanisms;

- experimental results published by Qi et al. [13] were used to determine the change in cathodic activation overpotential with $\mathrm{CO}$ crossover in the membrane.

The simulated results agree well with experimental results of the Ballard Mark IV fuel cell obtained by Amphlett et al. [5]. Model predictions for fuel feeds contaminated with $\mathrm{CO}$ agree well with experimental results of Qi et al. [13] at low CO contamination.

The simulated results showed that the current multi-component diffusion PEMFC model has the potential to take almost all chemical constituents in the atmosphere into account simultaneously.

The model is at present limited to isothermal conditions only. The future work will include convective fluxes due to pressure gradients across the cell and incorporate heat-transfer management. Pressure gradients are likely to cause a convective flux of water in the membrane opposite in direction to the water being dragged by protons across the membrane, thereby unifying membrane hydration. Correspondingly, the membrane resistance should decrease. Temperature gradients, on the other hand, will cause evaporative losses where the loss of membrane hydration will lead to a loss of membrane conductivity. Liquid-water transport will also be considered, which will extend the model to cover the effects of localized flooding. Localized condensation caused by the partial pressure of water exceeding the saturation vapour pressure will present a barrier to mass transport in the electrodes, reducing the availability of reactant species at the catalyst sites, thereby leading to a loss in performance. Inclusion of such effects will broaden the applicability of the model. From a 2D perspective, the computational models of Natarajan et al. [23] and Bradean et al. [24] illustrated that liquid water formation is most likely to propagate in the region of the cathode diffuser directly adjacent to the solid shoulder of the graphite plate. This is due to the fact that this region of the diffuser is not exposed to the gas flow in the cathode channel, thereby hindering water removal and causing an accumulation in water content. The water then condenses and leads to the localized formation of liquid water, which is a barrier to oxygen diffusion. This has the effect of reducing the absolute value of the local current density over the region of the shoulder [23]. Such effects of localized water formation were not considered in our 1D model, but will be addressed in future work. Further theory-based consideration will also be given to electrode kinetics acknowledging the presence of $\mathrm{CO}$ in both the catalyst layers. A first-step attempt has been made in this paper to define the mechanism of $\mathrm{CO}$ flux in the membrane from a theoretical perspective.

\section{REFERENCES}

1 Fuller, T. F. and Newman, J. Water and thermal management in solid-polymer-electrolyte fuel cells. J. Electrochem. Soc. 1993, 140, 1218-1224.

2 Bernardi, D. M. and Verbrugge, M. W. Mathematical model of a gas-diffusion electrode bonded to a polymer electrolyte. Am. Inst. Chem. Eng., 1991, 37, 1151.

3 Bernardi, D. M. and Verbrugge, M. W. A mathematical model of the solid-polymer-electrolyte fuel cell. J. Electrochem. Soc., 1992, 139, 2477-2491.

4 Springer, T. E., Zawodzinksi, T. A., and Gottesfeld, S. Polymer electrolyte fuel cell model. J. Electrochem. Soc., 1991, 138, 2334.

5 Amphlett, J. C., Baumert, R. M., Mann, R. F., Peppley, B. A., Roberge, P. R., and Harris, T. J. Performance modeling of the Ballard Mark IV solid polymer electrolyte fuel cell. J. Electrochem. Soc. 1995, 142, 1-8.

6 Yi, J. S. and Nguyen, T. V. Multicomponent transport in porous electrodes of proton exchange membrane fuel cells using the interdigitated gas distributors. J. Electrochem. Soc. 1999, 146(1), 38-45.

7 Bradean, R. and Promislow, K. Transport phenomena in the porous cathode of a proton exchange membrane fuel cell. Numer. Heat Transfer, Part A 2002, 42, 121-138.

8 Dhar, H. P., Christner, L. G., Kush, A. K., and Maru, H. C. Performance study of fuel cell Pt-on-C anode in presence of $\mathrm{CO}$ and $\mathrm{CO}_{2}$, and calculation of adsorption parameters for CO. J. Electrochem. Soc., 1986, 133(8), 1574-1582.

9 Vogel, W., Lundquist, L., Ross, P., and Stonehart, P. The rate controlling step for electrochemical oxidation of hydrogen on Pt in acid and poisoning of the reaction by CO. Electrochim. Acta, 1975, 20, 79-93.

10 Wang, J.-T. and Savinell, R. F. Simulation studies on the fuel electrode of a $\mathrm{H}_{2}-\mathrm{O}_{2}$ electrolyte fuel cell. Electrochim Acta, 1992, 37(15), 2737-2745. 
11 Springer, T. E., Rockward, T., Zawonzinski, T. A., and Gottesfeld, S. Model for polymer electrolyte fuel cell operation on reformate feed. J. Electrochim. Soc. 2001, 148(1), A11-A23.

12 Liu, P., Logadottir, A., and Nørskov, J. K. Modelling the electro-oxidation of $\mathrm{CO}$ and $\mathrm{H}_{2} / \mathrm{CO}$ on $\mathrm{Pt}, \mathrm{Ru}, \mathrm{PtRu}$ and Pt3Sn. Electrochim. Acta, 2003, 48, 3731-3742.

13 Qi, Z., He, C., and Kaufman, A. Effect of CO in the anode fuel on the performance of PEM fuel cell cathode. J. Power Sources, 2002, 111, 239-274.

14 Si, Y., Kunz, H. K., and Fenton, J. M. Nafion-teflon$\mathrm{Zr}\left(\mathrm{HPO}_{4}\right)_{2}$ composite membranes for high-temperature PEMFCs. J. Electrochim Soc., 2004, 151(4), A623-A634.

15 Berger, C. Handbook of Fuel Cell Technology, 1968 (Prentice-Hall, Inc., Englewood Cliffs, New Jersey).

16 Newman, J. Electrochemical Systems, 1973 (PrenticeHall, Inc., Englewood Cliffs, New Jersey).

17 Slattery, J. C. and Bird, R. B. Calculation of the diffusion coefficient of dilute gases and of the self-diffusion coefficient of dense gases. Am. Inst. Chem. Eng., 1958, 4, $137-141$.

18 Cunningham, R. E. and Williams, R. J. J. Diffusion in Gases and Porous Media, 1980 (Plenum Press, New York).

19 de Bruijn, F. A., Papageorgopoulos, D. C., Sitters, E. F., and Janssen, G. J. M. The influence of carbon dioxide on PEM fuel cell anodes. J. Power Sources, 2002, 110, 117-124.

20 Davis, M. W. Development and evaluation of a test apparatus for fuel cells. M.Sc. thesis, Virginia Polytechnic Institute and State University, 2000.

21 Moore, J. M., Adcock, P. L., Lakeman, B., and Mepsted, G. O. The effects of battlefield contaminants on PEMFC performance. J. Power Sources, 2000, 85, 254-260.

22 Oetjen, H.-F., Schmidt, V. M., Stimming, U., and Trila F. Performance data of a proton exchange membrane fuel cell using $\mathrm{H}_{2} / \mathrm{CO}$ as fuel gas. J. Electrochem. Soc. 1996, 143(12), 3838-3842.

23 Natarajan, D. and Van Nguyen, T. A two-dimensional, two-phase, multicomponent, transient model for the cathode of a proton exchange membrane fuel cell using convenctional gas distributors. J. Electrochem. Soci., 2001, 148(12), A1324-A1335.

24 Bradean, R., Promislow, K., and Wetton, B. Transport phenomena in the porous cathode of a proton exchange membrane fuel cell. Numer. Heat Transfer, Part A 2002, 42, 121-138.

\section{APPENDIX}

\section{Notation}

$a$

A

$c_{\mathrm{i}}$

$c_{\text {drag }}$
$D_{\mathrm{i}}$

$D_{\mathrm{ij}}$

E

$E^{\circ}$

F

$\Delta G_{\mathrm{c}}$

H

$i$

I

$j_{0}$

J

$k^{\prime}$

K

$M_{\mathrm{i}}$

$n$

$\dot{n}_{\mathrm{i}}$

$p_{\mathrm{i}}$

$P$

$R$

$R^{\text {internal }}$

$s$

$T$

$y_{\mathrm{i}}^{\mathrm{E}-\mathrm{X}}$

$y_{\mathrm{i}}^{\prime}$

$z$

$\alpha_{\mathrm{A}}$

$\alpha_{\mathrm{C}}$

$\alpha_{\mathrm{i}}^{\mathrm{E}}$

$\gamma$

$\eta$

$\Theta$

$\lambda$

$\mu_{\mathrm{i}}$

$\xi$

$\rho_{\text {dry }}$

$\sigma$

$\varphi_{\mathrm{n}}$

\section{Subscripts}

hydrogen ion flux in the

membrane $\left(\mathrm{cm}^{2}\right)$

concentration of species i $\left(\mathrm{mol} / \mathrm{cm}^{3}\right)$

electro-osmotic drag coefficient

(number of water molecules carried

per hydrogen ion)
C

i

j

m

$\mathrm{n}$

diffusivity of species i $\left(\mathrm{cm}^{2} / \mathrm{s}\right)$

diffusivity of species pair ij $\left(\mathrm{cm}^{2} / \mathrm{s}\right)$

thermodynamic equilibrium

potential (V)

standard state potential (V)

Faraday constant (96 $484 \mathrm{C}$ )

standard-state free energy of chemisorption of dissolved hydrogen

per mole of hydrogen $(\mathrm{J} / \mathrm{mol})$

crossover-loss gradient (per ppm)

current (A)

molar flux of water produced at the

cathode $\left(\mathrm{mol} / \mathrm{cm}^{2} \mathrm{~s}\right)$

exchange current density $\left(\mathrm{A} / \mathrm{cm}^{2}\right)$

current density $\left(\mathrm{A} / \mathrm{cm}^{2}\right)$

parametric coefficient for anodic exchange current density

parametric coefficient for cathodic

exchange current density

molecular weight of species i $(\mathrm{g} / \mathrm{mol})$

number of equivalents

flux of species i $\left(\mathrm{mol} / \mathrm{cm}^{2} \mathrm{~s}\right)$

partial pressure of species $\mathrm{i}(\mathrm{Pa})$

total pressure $(\mathrm{Pa})$

molar gas constant $(8314.3 \mathrm{~J} / \mathrm{mol} \mathrm{K})$

internal resistance $(\Omega)$

extension parameter, 0.0126

temperature $(\mathrm{K})$

mole fraction of species $\mathrm{i}$ in electrode

$\mathrm{E}$ at station number $\mathrm{X}$

concentration in part per million

(ppm) of species $\mathrm{i}$

transverse cell co-ordinate

anodic transfer coefficient

cathodic transfer coefficient

flux ratio of species $i$ to species $n$

for electrode $\mathrm{E}$

transfer coefficient

overpotential (V)

CO-induced degradation factor

membrane water content

electrochemical potential of

species i $(\mathrm{J} / \mathrm{mol})$

parametric coefficient

dry membrane density $\left(\mathrm{g} / \mathrm{cm}^{3}\right)$

conductivity $(\Omega / \mathrm{cm})$

stoichiometry of species $n$

critical property

species i

species $j$

membrane

reductant or oxidant species 


\section{Superscripts}

A anode

C cathode

$\mathrm{CH} \quad$ channel

E electrode
E-1 or 2 interface 1 or 2 of electrode $\mathrm{E}$

Gen generated

IN inlet

Sat saturation

dry state 